\title{
Non-destructive tests of fibre-cement materials structure with the use of scanning electron microscope
}

\section{Keywords:}

accident;

fiber cement boards;

acoustic emission;

artificial neural networks;

high temperature

\begin{abstract}
The article presents the NDT results of research on the influence of high temperature on the destruction of the structure of fiber-cement board as a result of the failure of a tunnel furnace. Two fiber cement boards were tested. There was a plate in a tunnel furnace during a failure, and reference plate dried in normal conditions. The research used acoustic emission method in combination with artificial neural networks. Interesting research results were obtained, which allowed to observe visible changes in the structure of the tested panels under the influence of high temperature. An important application from the point of view of building practice was formulated.
\end{abstract}

\section{Introduction}

Since the beginning of the last century, one of the most used products in constructions are the fiber-cement boards, which were developed by Ludwik Hatschek. From the beginning, this product was characterized by durability, low weight, resistance to moisture and non-flammability [1]. It has become one of the most popular building materials used to cover roofs. These boards had one significant drawback, namely the composition of asbestos, which, as it turned out, has carcinogenic properties. For this reason, asbestos was replaced in the 90's with safe fibers, mainly cellulose ones. Today's fibrer-cement boards consist of cement, cellulose fibers, synthetic fibers and various additives and admixtures, and constitute a completely different and innovative

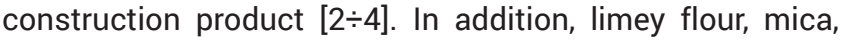
perlite, kaolin, and microsphere are present in the composition of fiber-cement boards [5]. Fiber-cement boards are used in construction primarily as: external facade cladding in a ventilated façade system, boards for balcony and terrace covers, roof coverings as well as internal linings $[5,6]$. Fiber-cement boards just like many construction products are a composite material. For this reason, they are exposed to defects and damages at the production stage, e.g. as a result of equipment failure. This has a significant impact on their properties.
During the production process, fibre-cement boards pass through many stages, which are very complex. This is described in detail in [5]. The final stage of production is the drying of boards in a tunnel kiln (Fig. 1), where the boards reach maturing in special climatic chambers. This is to get rid of excess moisture from the panels before painting them.

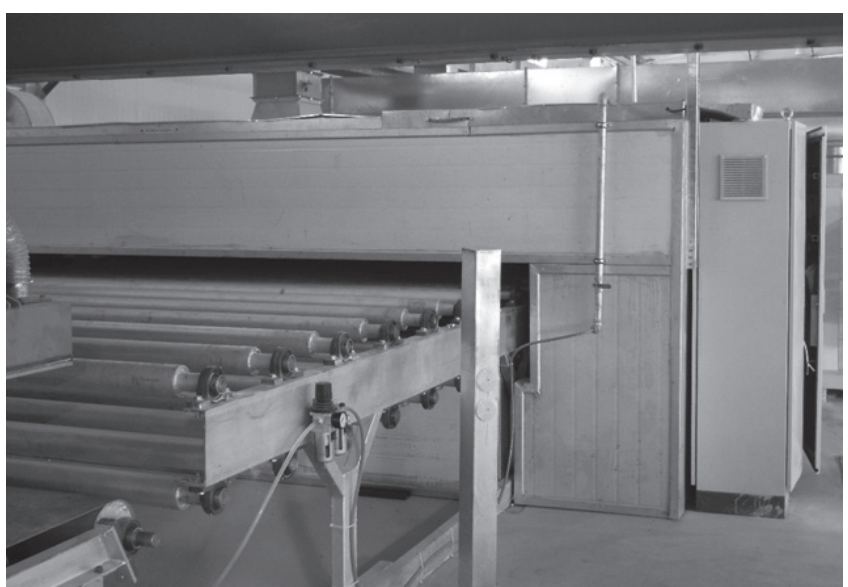

Fig. 1. View of a tunnel kiln for drying fiber-cement boards 
The drying process involves the displacement of fibre-cement boards on transport rolls through the tunnel kiln chambers. The board residence time in the kiln is approx. $10 \mathrm{mi}-$ nutes, at a set temperature of 160 to $180{ }^{\circ} \mathrm{C}$. However, an emergency situation may occur, e.g. in the form of kiln failure that will affect the technological process. The situation is described below in which, during the drying process, the control of the kiln and drive of the board transporting device has failed. This caused the fiber-cement boards to "get stuck" inside the kiln for a much longer period than the drying technology anticipated. It should be clarified that the boards in the tunnel kiln during the standard drying process stay in it for about 5 minutes at a temperature of $160{ }^{\circ} \mathrm{C}$ and about 5 minutes at $180^{\circ} \mathrm{C}$ and are moved along the hot air blowers. As a result of the failure, a significant part of fiber-cement boards stayed for more than 30 minutes directly under the hot air blowers until the kiln was switched off and cooled. It was feared that the lack of temperature control caused an increase of up to over $200{ }^{\circ} \mathrm{C}$ and had a destructive effect on the structure of fiber-cement boards. Previous studies of fibre-cement boards concern mainly the determination of standard physical and mechanical parameters and the influence of operating factors such as soaking and drying cycles, freezing and thawing cycles, heating and sprinkling effects by testing only bending strength $[7,8]$. There are also a few results of research carried out using non-destructive methods, including ultrasound methods and acoustic emission methods $[9,10]$.

\section{Tests description}

Two fiber-cement boards were tested. These were: a board labeled as "board A", which was in the tunnel kiln during the aforementioned failure, and the reference board dried in correct conditions and marked as "board R". For the comparative studies, an "R" of the same type and from the same production series as "A" was used. From both boards, 5 samples were taken for testing. Each had a dimension of $20 \times 100 \mathrm{~mm}$. Then, tests were carried out using the acoustic emission method in a three-point bending test. The test stand constructed for this purpose is shown in figure 2 . In addition, the values of MOR bending strength were determined for the tested panels according to the reliance given in the standard [4].

During the test, the PASCAL MICROPRASA $\mu \mathrm{P}-3 \mathrm{kN}$ testing machine was used, having a load range from 0 to $3 \mathrm{kN}$ and a constant traverse displacement of $0.1 \mathrm{~mm} / \mathrm{min}$. Descriptors of EA as a function of time were subject to registration

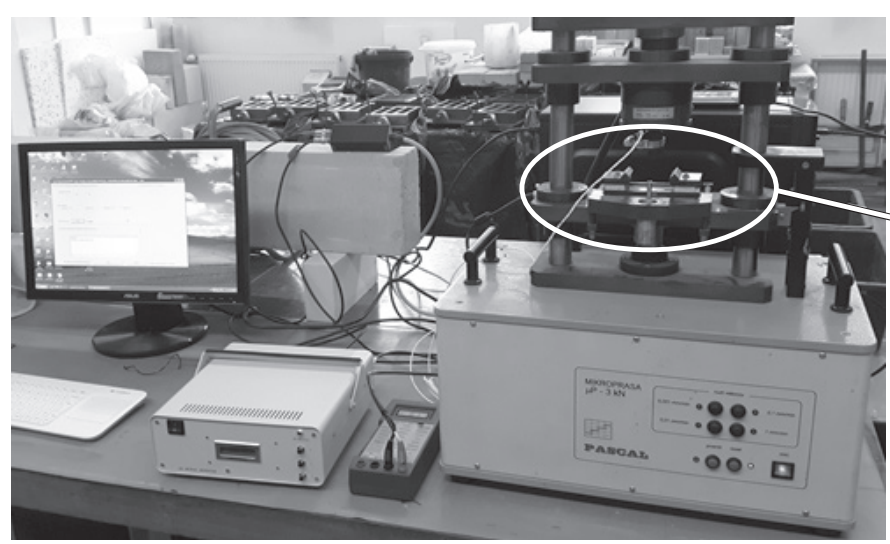

and those were the rate of events $N_{\text {ev, }}$ and the sum of events $\Sigma \mathrm{N}_{\mathrm{ev}}$, as well as the characteristics of the acoustic spectra of recorded events of EA. Then, in order to demonstrate the changes taking place in the structure of boards under the influence of high temperature, artificial one-way, multi-layer neural networks with retrograde error propagation were used.

\section{Research results and their analysis}

List of the averaged values of the MOR bending strength and the exemplary sum of events $\Sigma \mathrm{N}_{\mathrm{ev}}$ are presented in the table I.

Figure 3 shows the registered dependence $\sigma-\varepsilon$ for board A and board R.

As can be seen by analyzing the results collected in Table $I$ and Figure 3, the difference in MOR bending strength between boards is about $5 \%$, and it can be assumed that it is within the limits of measurement errors. This does not cause any anxiety, but it also does not allow to conclude, whether during the kiln failure destructive changes in the structure

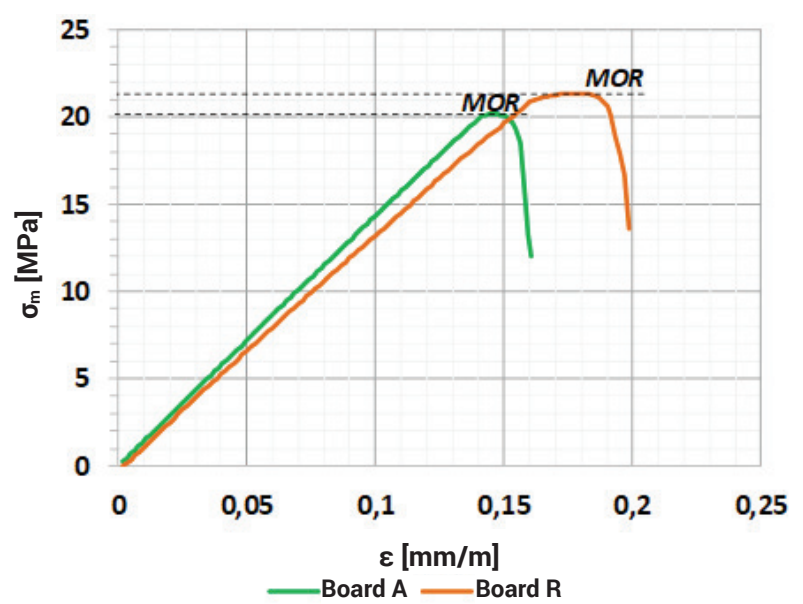

Fig. 3. An example of the dependence of $\sigma-\varepsilon$ for bending on board $A$ and board $\mathrm{R}$

Table I. Comparison of the average value of bending strength of the MOR and an exemplary sum of events $\sum \mathrm{N}_{\mathrm{ev}}$

\begin{tabular}{|c|c|c|}
\hline $\begin{array}{c}\text { Board's } \\
\text { designation }\end{array}$ & $\begin{array}{c}\text { MOR bending } \\
\text { strength [MPa] }\end{array}$ & $\begin{array}{c}\text { Sum of events } \\
\sum \mathrm{N}_{\mathrm{ev}}[-]\end{array}$ \\
\hline Board A & 20,17 & 508 \\
\hline Board R & 21,36 & 694 \\
\hline
\end{tabular}

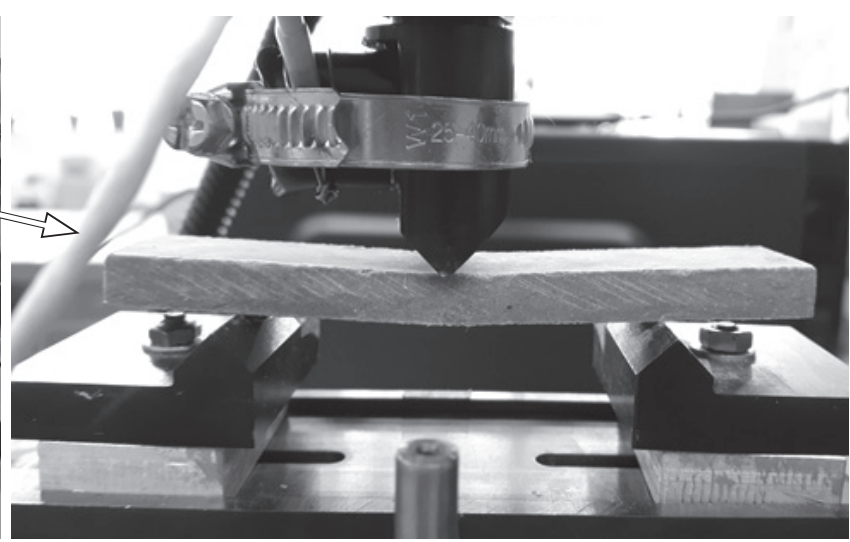

Fig. 2. View of the test bench for measurement with the acoustic emission method (left) along with the enlargement of the fiber-cement board sample during the test (right) 
Table II. List of the results of the identified events for the A and R board after the process of teaching the artificial neural network

\begin{tabular}{|c|c|c|c|c|}
\hline $\begin{array}{c}\text { Board's } \\
\text { designation }\end{array}$ & $\begin{array}{c}\text { Sum of all registered } \\
\text { events } \sum \mathbf{N}_{\mathrm{ev}}\end{array}$ & $\begin{array}{c}\text { Sum of recognized events } \\
\Sigma \mathbf{N}_{\mathrm{ev}, \mathrm{r}}\end{array}$ & $\begin{array}{c}\text { Sum of events ascribed } \\
\text { to fibre breaking } \sum \mathbf{N}_{\mathrm{ev}, \mathrm{f}}\end{array}$ & $\begin{array}{c}\text { Sum of events ascribed } \\
\text { to matrix breaking } \sum \mathbf{N}_{\mathrm{ev}, \mathrm{m}}\end{array}$ \\
\hline Board A & 508 & 498 & 414 & 84 \\
\hline Board R & 694 & 670 & 634 & 36 \\
\hline
\end{tabular}

of the dried A board took place. For this reason, it was decided to continue the study and analyze the registered EA events using artificial neural networks. The final stage in the analysis of EA signals was the recognition of registered events and their attribution to the signals accompanying the cracking of the fibers and the cement matrix. Figures 4 and 5 show the record of the rate of events $N_{\text {ev }}$ and bending stress $\sigma_{m}$ as a function of time for board $A$ and board $R$, together with the applied identification of the standard spectral characteristics.

List of the results of the identified events for the $A$ and $R$ board after the process of teaching the artificial neural network is shown in Table II.

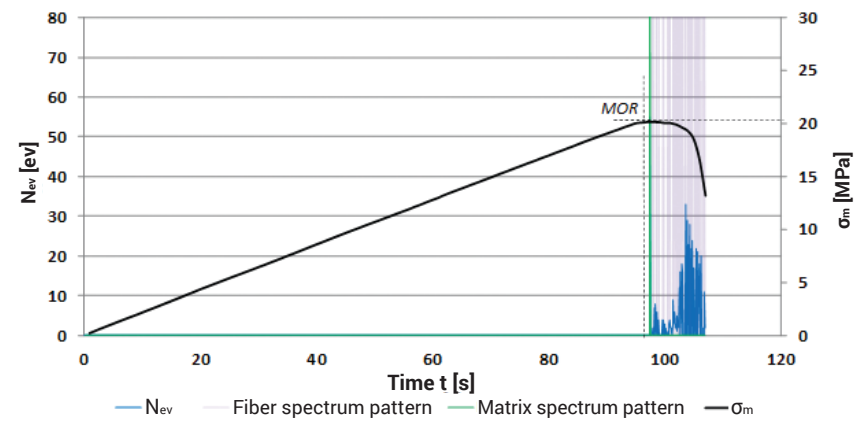

Fig. 4. Recording of the rate of events $\mathrm{N}_{\mathrm{ev}}$ and bending stresses $\sigma_{\mathrm{m}}$ in the time function for the board $A$ with the identification of the standard spectral characteristics
From the analysis of Figures 4 and 5 and the results presented in Table II, it can be seen that for board A during the three-point bending test, a significantly smaller number of events occurred in the cracking of fibers by approx. $30 \%$ compared to the board $\mathrm{R}$. It can therefore be concluded that due to the failure of tunnel kiln, which caused a high temperature effect, the structure of the fiber-cement board has been destroyed. This destruction involves the burning of part of the fibers and thus the change of technical parameters of the fiber-cement board.

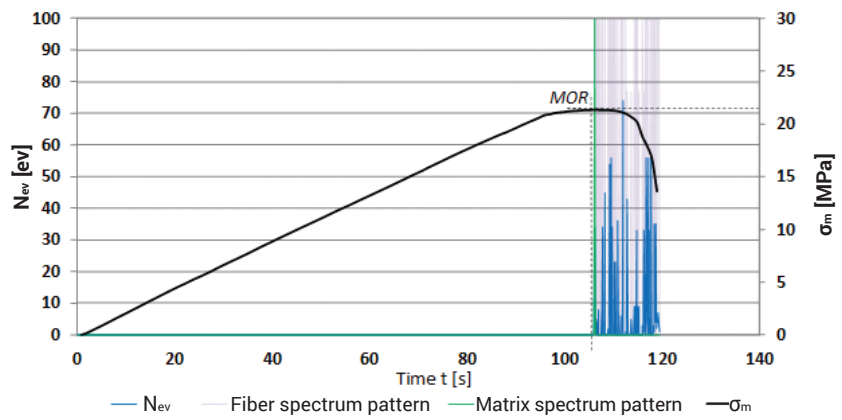

Fig. 5. Recording of the rate of events $N_{\mathrm{ev}}$ and bending stresses $\sigma_{\mathrm{m}}$ in the time function for the board $R$ with the identification of the standard spectral characteristics

\section{Conclusions}

This paper presents the results of research on the structure of two types of fiber-cement boards. One board subjected to high temperatures due to failure of the tunnel kiln, and the reference board, which was dried in the right conditions. The method of acoustic emission with the additional use of artificial neural networks was used for the research. The obtained interesting results of the research allowed to observe the changes taking place in the structure of the tested boards under the influence of high temperature. It allowed to formulate the conclusion that standard tests of fibre-cement boards basically boil down to determining the MOR bending strength, and the evaluation of the boards on this basis is insufficient and can lead to a situation in which the damaged boards will be built into the building.

\section{References}

[1] Information from the website https://de.wikipedia.org/wiki/Ludwig_Hatschek.

[2] Information from the website https://www.equitone.com

[3] Information from the website https://www.cembrit.com.

[4] EN 12467 - Cellulose fibre cement flat sheets. Product specification and test methods, (2018)

[5] Z. Ranachowski, K. Schabowicz, The Fabrication, Testing and Application of fibre cement boards, Cambridge Scholars Publishing, Newcastle (2018).

[6] K. Schabowicz, T. Gorzelańczyk, M. Szymków, Elewacje wentylowane, Architektura Murator (2017), nr 6, dod. Warsztat Architekta nr 3, 36-53.

[7] M. Ardanuy, J. Claramunt, R.D. Toledo Filho, Cellulosic Fiber Reinforced Cement-Based Composites: A Review of Recent Research, Construction and Building Materials (2015) vol. 79, 115-28.
[8] J. Claramunt, M. Ardanuy, J.A. García-Hortal, Effect of drying and rewetting cycles on the structure and physicochemical characteristics of softwood fibres for reinforcement of cementitious composites, Carbohydrate Polymers (2010), 79, 200-205.

[9] R. Drelich, T. Gorzelańczyk, M. Pakuła, K. Schabowicz, Automated Control of Cellulose Fibre Cement Boards with a Non-Contact Ultrasound Scanner, Automation in Construction (2015), 57, 55-63.

[10] T. Gorzelańczyk, K. Schabowicz, M. Szymków, Nieniszczące badania płyt włóknisto-cementowych z wykorzystaniem emisji akustycznej, Welding Technology Review (2016), vol. 88(10), 35-38. 